\title{
THE GERMANIC FIRST CLASS OF WEAK VERBS
}

\author{
FREDERIK KORTLANDT
}

1. The first weak class of Germanic continues two PIE. present stem formations, viz. ${ }^{*}$-ie/o- and ${ }^{\star}$-eie/o-, e.g.

$\begin{array}{lllll}\text { 3rd sg. } & { }^{*} \text { bugjepi } & { }^{*} \text { wurkjepi } & { }^{*} \text { nasejepi } & { }^{*} \text { kausejepi } \\ \text { 3rd pl. } & { }^{*} \text { bugjanpi } & { }^{*} \text { wurkjanpi } & { }^{*} \text { nasejanpi } & { }^{\star} \text { kausejanpi } \\ & \text { 'buy' } & \text { 'work' } & \text { 'save' } & \text { 'probe' }\end{array}$

The question to be answered in the following is: when did these two types merge?

2. The two types were redistributed according to the length of the stem in the attested languages, e.g. Gothic:

$\begin{array}{lllll}\text { 3rd sg. } & \text { bugjip } & \text { waurkeip } & \text { nasjip } & \text { kauseip } \\ \text { 3rd pl. } & \text { bugjand } & \text { waurkjand } & \text { nasjand } & \text { kausjand }\end{array}$

It is reasonable to assume that bugjip, kauseip, and the $3 \mathrm{rd} \mathrm{pl}$. forms are phonetically regular. This suggests that ${ }^{\star} e$ was raised to $i$, intervocalic ${ }^{\star} j$ was lost, and the high front vowel became nonsyllabic before $a$. Conversely, ${ }^{*} j$ became vocalic in waurkeip, lengthening the thematic vowel. This must have been a phonetic development because it is also found in the nominal inflection. It eliminated the difference between the two types of present stem formation after long verb stems. In the case of short verb stems, the elimination of the difference must have been due to an analogical development because the form nasjip can hardly be phonetically regular, as will be argued in the following.

3. The 2nd sg. imperative ending -ei, which is uniform after long and short verb stems, can only be derived from PIE. ${ }^{*}$-eie because ${ }^{*}$-ie would yield $-i$, as is clear from the vocative of the io-stems, e.g. hairdi 'shepherd', and related forms. Consequently, verbs with a present stem in ${ }^{*}$-ie/o- must have adopted the imperative in ${ }^{*}$-eie at a stage when the latter still represented a distinct flexion type. This poses a problem with respect to the chronology and the motivation of the required analogical development.

4. Chronologically, the simplest assumption is that verbs of the type of bugjan and waurkjan adopted the imperative of nasjan and kausjan after the loss of final ${ }^{\star}-e$, which eliminated the thematic vowel from the imperative. As a result of this phonetic development, the imperative in ${ }^{*}-i,{ }^{*}-e i$ became somewhat isolated from the indicative paradigm and therefore more easily subject to analogical pressure. When intervocalic ${ }^{*} j$ was subsequently lost and the two types of present stem merged before the low thematic vowel $a$, there was little reason to keep the two types distinct in the imperative.

5. The motivation for generalizing the long ending - ei rather than the short ending ${ }^{*}-i$ was simply the relative frequency of the two types. Krause lists 12 primary verbs versus 
42 causatives, intensives and iteratives, beside 46 denominatives (1953: 225-227). The latter may belong to either type, cf. Gr. poimaínō 'herd' of poimến, philéo 'love' of phílos, and may have been subject to redistribution in Proto-Germanic times. The generalization of -ei may have been facilitated by the vocalization of ${ }^{*} j$ in waurkeis, waurkeip, which induced the transition to the other type.

6. Just as ${ }^{*}$-eie yielded -ei, PIE. ${ }^{\star}$-eies yielded -eis in nom.pl. naweis of naus 'corpse'. This makes the conclusion that nasjip replaces an earlier form ${ }^{\star}$ naseip practically inevitable. This analogical development again poses a problem of chronology and motivation. It is clear that it must have been posterior to the generalization of the long imperative ending -ei, which would otherwise be a quite incomprehensible development.

7. After the neutralization of the opposition between /i/ and / $/$ in waurkeip and nasjand, the flexion of nasjan differed from that of bugjan only in those forms where long verb stems automatically took -ei- alternating with -ja-. The flexion of bugjan was of greater regularity because it always had a stem-final $-j$ - before the thematic vowel. Moreover, the same flexion was found in strong verbs with a present stem in $-j$-, e.g. bidjan 'pray', hafjan 'raise'. Krause lists 17 verbs of this type (4 primary weak verbs, 4 denominatives with a vocalic stem, and 7 strong verbs with a short stem, to which * sitjan and ${ }^{*}$ ligjan must be added on the evidence of the North and West Germanic languages) versus 9 causatives and intensives, beside 6 denominatives with a consonantal short stem (1953: 219-220 and 225-227). It appears that the substitution of nasjip for ${ }^{*}$ naseip was determined both by the tendency toward regularity of the paradigm and by the relative frequency of the types. The substitution may or may not have taken place in the West Germanic languages, which lost ${ }^{*} j$ before $i$.

8. Thus, I claim that the phonemic distinction between -ji- (from ${ }^{\star}-j e-$ ) and -ei- (from ${ }^{\star}$-e $i$ - and $\left.{ }^{\star}-\bar{i}-\right)$ was never lost after short stems. There is no reason to assume a ${ }^{\star}-j$ - at any stage in the development of the word marei 'sea', which represents the neuter ${ }^{*}$ mari plus the PIE. suffix ${ }^{\star}-H_{1} n-$. Similarly, verbal nouns such as naseins 'salvation' do not replace earlier ${ }^{*}$ nasjins from ${ }^{*}$-jen-, as is sometimes assumed, but represent a lost neuter ${ }^{\star}$ nasi plus the suffix ${ }^{\star}-H_{1} n$-. The form ${ }^{\star}$ nasi, which is also found as the first member of a compound in the preterite, can be identified with the Vedic passive aorist in - $i$, as I have indicated elsewhere (1981: 128 , fn. 1). There is no evidence for a sequence $-j i$ - which is older than the raising of ${ }^{*} e$ to $i$ in unstressed syllables.

9. The neutralization of the opposition between /i/ and / $/$ / took place not only before $a$, but also before other back vowels, cf. especially nom.pl. sunjus of sunus 'son', PIE. *-eues. Since $j$ after a long stem was not excluded before back vowels, it was bound to spread to the position before front vowels. This is what happened in gen.sg. andbahtjis 'service', gawairpjis 'peace' next to andbahteis, gawairpeis, also reikjis 'power', arbjis 'heritage', fiskjins 'fisher', bandjins 'prisoner', and similarly in the adjective.

10. In conclusion, I assume the following chain of developments:

(1) loss of final ${ }^{\star}-e$,

(2) raising of ${ }^{\star} e$ to $i$ and loss of intervocalic ${ }^{\star} j$,

(3) vocalization of ${ }^{*} j$ after a long stem before front vowels, 
(4) desyllabification of ${ }^{\star}-i$ before back vowels,

(5) generalization of the long imperative ending $-e i$,

(6) analogical introduction of stem-final $j$ before front vowels.

The last development finally eliminated the difference between the flexion types of bugjan and nasjan. Though the West Germanic evidence for the developments (5) and (6) is inconclusive as a result of subsequent changes, the difference between Old High German 2nd sg. neris 'save' and subj. nāmìs 'took' seems to reflect the one between Gothic nasjis and nemeis quite faithfully.

Leiden University

\section{REFERENCES}

Kortlandt, F.

$1981 \quad$ 1st sg. middle ${ }^{\star}-H_{2}$. Indogermanische Forschungen 86, 123-136.

Krause, W.

1953 Handbuch des Gotischen. München: Beck. 